\title{
IN VIVO EVALUATION OF QUINAPRIL TRILAYERED MATRIX TABLETS
}

\author{
ASHWIN K*, RAMA MOHAN REDDY T
}

Department of Pharmacy, Mewar University, Chittorgarh, Rajasthan, India. Email: dbpathi71@gmail.com

\author{
Received: 08 May 2021, Revised and Accepted: 04 June 2021
}

\begin{abstract}
Objective: The aim was to design, formulate, and evaluate the trilayer matrix tablets incorporated with quinapril for extend drug release.

Methods: Quinapril trilayer matrix tablets were formulated using design of experiment software wherein initially 27 formulations (QF1-QF27) were designed for active layer from which one best formulation was chosen based on drug content, swelling index and in vitro release studies. The chosen formulation was formulated into extended release trilayed matrix tablet by varying proportions of polymers by direct compression and was evaluated for various physicochemical parameters, drug release. Best formulation was characterized for Fourier transform infrared (FTIR), stability, and pharmacokinetic study.
\end{abstract}

Results: Out of 27 formulations highest drug release was exhibited by QF16 (98.85\%) which was formulated into trilayer matrix tablets (AQF16HQF16). Out of which EQF16 was found to exhibit highest values with $98.42 \%$ swelling index, $99.56 \%$ drug content, and $99.72 \%$ drug release in 24 h. All quinapril trilayer formulations showed zero-order and first-order for marketed product. The optimized formulation EQF16 was found to exhibit no interaction with excipients interpreted by FTIR and no significant changes were observed after loading for stability. In vivo studies conducted using optimized formulation EQF16 attained peak drug concentration ( $\mathrm{T}_{\max }$ ) of $4.0 \pm 0.06$ and $1.0 \pm 0.03 \mathrm{~h}$ for the optimized and commercial formulations, respectively, while mean maximum drug concentration $\left(\mathrm{C}_{\max }\right)$ was $302.64 \pm 0.07 \mathrm{ng} / \mathrm{mL}$ and was significant (p<0.05) as compared to the quinapril marketed product formulation $358.78 \pm 0.75 \mathrm{ng} / \mathrm{mL}$.

Conclusion: Hence, quinapril was successfully formulated into trilayer matrix tablet and found to be stable.

Keywords: Quinapril, Hypertension, Hydroxypropyl methylcellulose, Release order kinetics, Pharmacokinetic studies.

(C) 2021 The Authors. Published by Innovare Academic Sciences Pvt Ltd. This is an open access article under the CC BY license (http://creativecommons.org/ licenses/by/4.0/) DOI: http://dx.doi.org/10.22159/ajpcr.2021v14i7.42002. Journal homepage: https://innovareacademics.in/journals/index.php/ajpcr

\section{INTRODUCTION}

The solid dosage forms of drug administrated orally are considered effective method of medication with the highest patient compliance. Numerous methods were adopted to modulate drug dissolution rate from the specific drug delivery system. Most of the orally administrated dosage forms exist as polymer matrix, reservoir, or multi-layer systems. The multi-layer matrix systems are emerging as potential designs for sustained oral drug delivery. These systems comprise of hydrophilic core embedding the drug molecules sandwiched between i-permeable polymeric layers (barrier-layer). These layers retard the interaction between solute and dissolution medium by minimizing the availability of surface for the release of solute and simultaneously checking solvent penetration rate. Subsequently the inflamed barriers erode leading to increase in surface area accessible for drug release thus simultaneously balancing the diffusion path length and area of drug release [1].

Hypertension has been identified by the World Health Organization (WHO) as one of the most significant risk factors for morbidity and mortality worldwide and is responsible for the deaths of approximately nine million people annually. In the UK, the National Institute for Health and Care Excellence (NICE) defines high blood pressure (BP), also known as hypertension, as a clinic BP of 140/90 mmHg or higher confirmed by a subsequent ambulatory BP monitoring daytime average (or home BP monitoring average) of 135/85 mmHg or higher [2].

Quinapril is an angiotensin-converting enzyme inhibitor indicated for the treatment of high BP (hypertension) and as adjunctive therapy in the management of heart failure. Quinapril $\mathrm{HCl}$ has short half-life $2 \mathrm{~h}$. The objective of the present research work of trilayered matrix tablet containing quinapril as a drug candidate which would remain for prolonged period of time thereby maximizing the drug release within the stipulated time [3].

\section{MATERIALS AND METHODS}

\section{Materials}

Quinapril was purchased from Hetero drugs Ltd, Hyderabad. Hydroxypropyl methylcellulose (HPMC) K15M, HPMC K 100M, sodium carboxy methyl cellulose, PVP K30. Magnesium stearate. Polyox WSR $\mathrm{N}$ 303, gellan gum. ethyl cellulose and talc were purchased from Gattefosse, Mumbai. All the reagents used were of analytical grade.

\section{Formulation of trilayered matrix tablets of quinapril $\mathbf{H C l}$}

The trilayered matrix tablets of Quinapril were prepared by direct compression method. The first step in the formulation was to develop the middle active layer so as to give at least $90 \%$ drug release during $12 \mathrm{~h}$. The release profile of this layer might not be of constant rate type but would be preferably of constantly falling rate type. This layer would then be sandwiched between barrier layers (Upper and Lower layers) so as to continue the drug release for $24 \mathrm{~h}$ [4].

Preparation of middle active layer of quinapril trilayered tablets Twenty-seven formulations (QF1-QF27) for active layer were prepared by direct compression method using 33 Response surface methods (three variables and three levels of polymers) by using Design of experiment software with polymers such as HPMC K100M, HPMC $\mathrm{K} 15 \mathrm{M}$, and Sodium Carboxy Methyl Cellulose. All the formulations were varied in concentration of polymers, magnesium stearate constituted in all the formulations. These materials were screened through \#60 and mixed together in motor using pestle. Final mixtures were compressed by using $10 \mathrm{~mm}$ diameter flat punches on a 16-station rotary tablet 
press. The prepared tablets were subjected to dissolution studies [5] (Fig. 1, Table 1)

\section{Preparation of upper and lower layers of quinapril trilayered} tablets

The barrier layers were formulated employing hydrophobic swellable polymer carnauba wax the swelling erosion modeling fillers which include water soluble dicalcium phosphate, EC, and gellan gum. The procedure adopted to make the compacts was through direct compressions. For the first procedure the carnauba wax, Gellan gum and the filler were mixed in mortar and lubricated with magnesium stearate [6]. Formulation of the upper and lower layers was depicted in Table 2.

Formulation of extended release trilayered tablets of quinapril The powder mixtures required for active and barrier layers were weighed accurately and thoroughly mixed using mortar and pestle for about $20 \mathrm{~min}$. Initially, the volume of die cavity; (10 $\mathrm{mm}$, round) was adjusted equivalence to the weight of trilayered matrix tablets $(300 \mathrm{mg})$. Then, the pre weighed amount of powder equivalent to bottom layer (100 mg) was taken and placed in the die cavity and slightly compressed for uniform spreading. The upper punch was lifted up and the granules equivalent to $100 \mathrm{mg}$ of the drug was placed over the bottom layer in the die cavity and again slightly compressed. The remaining volume of the die cavity was filled with pre weighed (100 mg) amount of powder equivalent to top layer and compressed with the full force of compression on rotary tablets press to obtain tri-layered tablets. Tri-layered matrix tablets of each composition were compressed and tested for their friability, Hardness, drug content, and drug release characteristics with a suitable number of tablets for each test [7].

\section{Evaluation tests}

Pre-compression evaluation tests

The lubricated blend was evaluated for angle of repose, bulk density, tapped density, Carr's index, and Hausner's ratio as per the reported procedures in reference [8-11].

\section{Post compression evaluation tests}

The compressed tablets were evaluated for weight variation, thickness, hardness, friability, and content uniformity and in vitro swelling studies as per the procedures mentioned in reference [12,13].

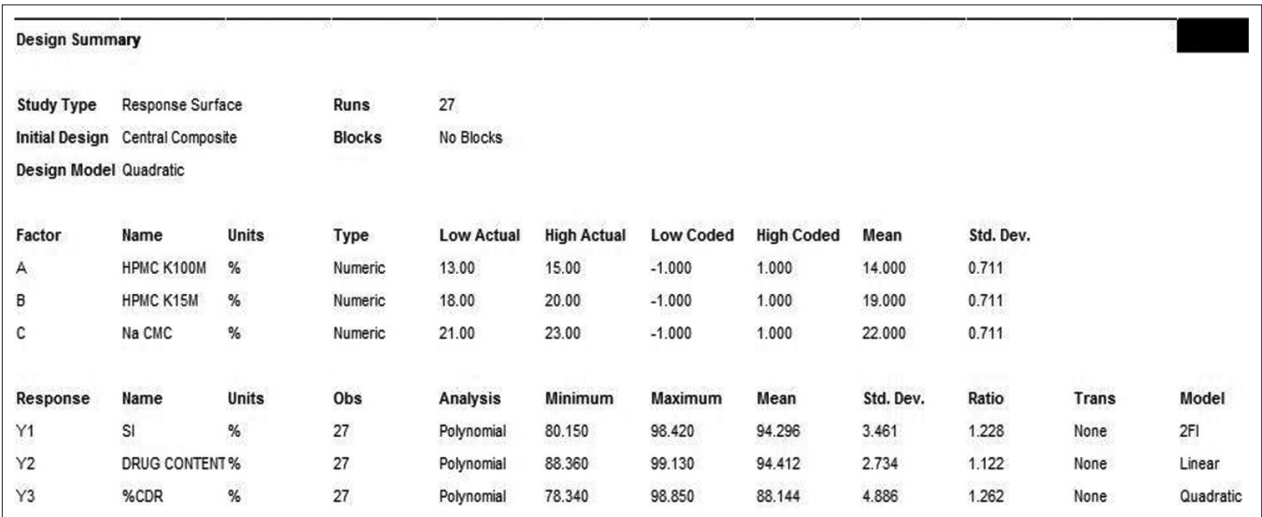

Fig. 1: List of dependent and independent variables in response surface methodology

Table 1: Formulation trials of extended release trilayered matrix tablets of quinapril

\begin{tabular}{|c|c|c|c|c|c|c|c|c|}
\hline F.NO & Quinapril & HPMC K100M & HPMC K15M & Na. CMC & PVP K-30 & Dicalcium phosphate & Mg Stearate & Total \\
\hline QF1 & 40 & 39 & 54 & 63 & 12 & 86 & 6 & 300 \\
\hline QF2 & 40 & 45 & 57 & 66 & 12 & 74 & 6 & 300 \\
\hline QF3 & 40 & 39 & 60 & 63 & 12 & 80 & 6 & 300 \\
\hline QF4 & 40 & 45 & 60 & 63 & 12 & 74 & 6 & 300 \\
\hline QF5 & 40 & 39 & 54 & 69 & 12 & 80 & 6 & 300 \\
\hline QF6 & 40 & 45 & 54 & 69 & 12 & 74 & 6 & 300 \\
\hline QF7 & 40 & 39 & 60 & 69 & 12 & 74 & 6 & 300 \\
\hline QF9 & 40 & 39 & 57 & 66 & 12 & 80 & 6 & 300 \\
\hline QF10 & 40 & 45 & 57 & 66 & 12 & 74 & 6 & 300 \\
\hline QF11 & 40 & 42 & 53 & 66 & 12 & 81 & 6 & 300 \\
\hline QF12 & 40 & 42 & 54 & 63 & 12 & 83 & 6 & 300 \\
\hline QF13 & 40 & 42 & 57 & 63 & 12 & 80 & 6 & 300 \\
\hline QF14 & 40 & 42 & 57 & 69 & 12 & 74 & 6 & 300 \\
\hline QF15 & 40 & 45 & 57 & 69 & 12 & 71 & 6 & 300 \\
\hline QF16 & 40 & 42 & 57 & 66 & 12 & 77 & 6 & 300 \\
\hline QF19 & 40 & 42 & 57 & 67 & 12 & 76 & 6 & 300 \\
\hline QF20 & 40 & 39 & 57 & 66 & 12 & 80 & 6 & 300 \\
\hline QF21 & 40 & 42 & 54 & 66 & 12 & 80 & 6 & 300 \\
\hline QF22 & 40 & 42 & 57 & 63 & 12 & 80 & 6 & 300 \\
\hline QF23 & 40 & 42 & 57 & 68 & 12 & 75 & 6 & 300 \\
\hline QF24 & 40 & 39 & 57 & 66 & 12 & 80 & 6 & 300 \\
\hline QF25 & 40 & 45 & 54 & 69 & 12 & 74 & 6 & 300 \\
\hline QF26 & 40 & 39 & 57 & 69 & 12 & 77 & 6 & 300 \\
\hline QF27 & 40 & 45 & 60 & 66 & 12 & 71 & 6 & 300 \\
\hline
\end{tabular}


Table 2: Composition of quinapril trilayered matrix tablet

\begin{tabular}{|c|c|c|c|c|c|c|c|c|}
\hline Ingredients & AQF16 & BQF16 & CQF16 & DQF16 & EQF16 & FQF16 & GQF16 & HQF16 \\
\hline \multicolumn{9}{|c|}{ Middle active layer (QF16) (300 mg) } \\
\hline Quinapril & 40 & 40 & 40 & 40 & 40 & 40 & 40 & 40 \\
\hline HPMC K100M & 42 & 42 & 42 & 42 & 42 & 42 & 42 & 42 \\
\hline HPMC K15M & 57 & 57 & 57 & 57 & 57 & 57 & 57 & 57 \\
\hline Sodium CMC & 66 & 66 & 66 & 66 & 66 & 66 & 66 & 66 \\
\hline PVP K30 & 12 & 12 & 12 & 12 & 12 & 12 & 12 & 12 \\
\hline Di calcium phosphate & 77 & 77 & 77 & 77 & 77 & 77 & 77 & 77 \\
\hline \multicolumn{9}{|c|}{ Upper and lower layer (100 mg) } \\
\hline Carnauba wax & 10 & 15 & 20 & 25 & 30 & 35 & 40 & 45 \\
\hline Gellean Gum & 45 & 40 & 35 & 30 & 25 & 20 & 15 & 10 \\
\hline Ethyl cellulose & 15 & 15 & 15 & 15 & 15 & 15 & 15 & 15 \\
\hline Di Calcium Phosphate & 26 & 26 & 26 & 26 & 26 & 26 & 26 & 26 \\
\hline Magnesium stearate & 2 & 2 & 2 & 2 & 2 & 2 & 2 & 2 \\
\hline Talc & 2 & 2 & 2 & 2 & 2 & 2 & 2 & 2 \\
\hline
\end{tabular}

\section{In vitro drug dissolution study}

In vitro drug dissolution studies were carried out for both core middle layer (QF1-QF27) and prepared trilayer tablet formulations was carried out using USP Dissolution Apparatus Type II (Paddle) at speed $100 \mathrm{rpm}$ with $900 \mathrm{ml}$ of Phosphate buffer ( $\mathrm{pH}$ 6.8) as dissolution medium by maintaining at $37 \pm 0.5^{\circ} \mathrm{C}$. Aliquots of $5 \mathrm{ml}$ of dissolution medium were withdrawn at different time intervals, filtered, and replaced with fresh $5 \mathrm{ml}$ of dissolution medium. The amount of drug released was determined by UV spectrophotometer (Shimadzu UV 1800) at $224 \mathrm{~nm}[14]$.

\section{Kinetic model fitting}

To elucidate the mode and mechanism of drug release, the data from the in vitro release study were fitted into various kinetic models such as zero-order, first-order, Higuchi's, and Korsmeyer-Peppas model [15].

\section{Pharmacokinetic studies of quinapril in rabbit plasma Animal preparation}

Twelve New Zealand white rabbits of either sex rabbits were (weighing 2-3 kg) selected for this study, all the animals were healthy during the period of the experiment. Animals were maintained at room temperature $25^{\circ} \mathrm{C}, \mathrm{RH} 45 \%$, and $12 \mathrm{~h}$ alternate light and dark cycle with $100 \%$ fresh air exchange in animal rooms, uninterrupted power and water supply and rabbits were fed with standard diet and water ad libitum. An in vivo pharmacokinetic study was conducted in accordance with the ethical guidelines for investigations in laboratory animals and approved by the Institutional Animal Ethics Committee17 (IAEC NO IAEC/1657/CMRCP/T2/PhD-16/74).

\section{Study design}

Rabbits were randomly divided into two groups each group contains six animals. The rabbits selected for the study were housed in separate cages and had no medication for 2 weeks before the study. They were denied food and water during the study. The cages of rabbit were placed in $18 \mathrm{~h}$ light $/ 6 \mathrm{~h}$ dark conditions. The optimized ER tablets formulation (test patch) and marketed reference product tablet formulation containing quinapril dose equivalent to rabbit dose (5 mg) of the drug, were crushed and mixed with carboxymethylcellulose (CMC) $1 \% \mathrm{w} / \mathrm{v}$ solution, ensuring that rabbits consumed all the dose. Drug was prepared in a solution form and was administered through the feeding tube orally. The Group A rabbits were fed with quinapril optimized formulation and Group B fed with marketed reference product (Accupril $40 \mathrm{mg}$ ) with equivalent dose to animal body weight [16].

\section{Determination of quinapril in rabbit plasma by HPLC method}

The HPLC analysis was performed on a Shimadzu HPLC system and this system consists of a pump (Shimadzu 2550), a UV visible dedector (Shimadzu 2487) operating at $211 \mathrm{~nm}$ and an automatic sample injection system with $20 \mu \mathrm{L}$ injection volume (Hewlett-Packard, Avandale, PA). The chromatographic separation was performed at 25
oC using Hickrom C18 (4.6× $250 \mathrm{~mm}, 10 \mu \mathrm{m})$ analytical column. The mobile phase was a mixture of acetonitrile:0.067 M KH2PO4 buffer and adjusted to $\mathrm{pH} 2.5(40: 60, \mathrm{v} / \mathrm{v})$. The flow rate was $1.0 \mathrm{~mL} / \mathrm{min}$. Perindopril was used as an IS. A $20 \mu \mathrm{L}$ amount of each solution was injected and chromatograms were recorded. To determine the stationary phase, Hichrom C $18(250 \times 4.6 \mathrm{~mm}, 10 \mu)$ and Thermo MOS$2(250 \times 4.6 \mathrm{~mm}, 5 \mu)$ columns were tested. Hichrom C $18(250 \times 4.6 \mathrm{~mm}$, $10 \mu$ ) column was chosen because of the better peak symmetry ratio. For organic compound of mobile phase, methanol and acetonitrile were checked and acetonitrile was selected. Then, different ratios of acetonitrile were studied $(20,30,40$, and $50 \%$; v/v) and $40 \%$ (v/v) acetonitrile was approved. This ratio of acetonitrile provided shorter analysis time. Finally, mobile phase ratio was found to be acetonitrile: KH2PO4 (0.067 M; at pH 2.5) (40:60; v/v). Around the flow rates of $0.9 ; 1.0$; and $1.1 \mathrm{~mL} / \mathrm{min}, 1.0 \mathrm{~mL} / \mathrm{min}$ was selected as an optimum flow rate and perindopril were selected as IS. The optimum wavelength for detection was $211 \mathrm{~nm}$, at which the best detector responses for both drugs and the IS were obtained. The retention times were $4.52 \mathrm{~min}$ for QNP, 3.6 min for perindopril (IS) [17].

\section{RESULTS AND DISCUSSION}

Percentage drug content and swelling index

The $\%$ drug content of all quinapril core layer ranged from $92.12 \pm 0.78$ to $99.13 \pm 0.98 \%$ and the swelling index varied between $90.87 \pm 0.10$ and $98.42 \pm 0.069 \%$ with maximum value recorded for QF16.

\section{In vitro drug dissolution studies of core middle layer}

In vitro dissolution studies conducted for the core middle layer tablets of quinapril (RF1-RF27) is represented in figs. All 27 formulations exhibited complete drug release up to $12 \mathrm{~h}$. Out of all QF16 showed highest drug release of $98.85 \pm 1.52$. Based on drug content, swelling index and drug release QF16 were chosen as best active layer formulation for further studies (Figs. 2-5).

Physical evaluation of prepared powder blends of quinapril tablet All the parameters were found to be within limits.

The bulk densities of all the formulations AQF16 to HQF16 were measured and they are ranged from $0.50 \mathrm{~g} / \mathrm{cc}$ to $0.58 \mathrm{~g} / \mathrm{cc}$.

The tapped density of all the formulations AQF16 to HQF16 was measured and they are ranged from $0.54 \mathrm{~g} / \mathrm{cc}$ to $0.67 \mathrm{~g} / \mathrm{cc}$.

Angle of repose of all the formulations was found satisfactory result. The formulation EQF16 was found to be 20.22 having good flow property.

The compressibility index values were found to be in the range of $8-11 \%$.

The Hauser's ratio values were found to be in the range of 1.06-1.11\%. 
Physicochemical evaluation properties of quinapril trilayered tablets

The results of the physical tests of the prepared blends were within the limits.

The weight variation of all the formulations with in limit, the adequate tablet hardness is necessary requisite for consumer acceptance and handling.

The measured hardness of the tablets of each batch of all formulations, that is, AQF16 to HQF16 were ranged between 5.0 to $6.0 \mathrm{Kg} / \mathrm{cm}^{2}$.

The thickness of the tablets was found to be almost uniform in all formulations AQF16 to HQF16.

The friability of all prepared formulation is in between 0.54 and 0.65 . The friability properties limits are in between 0 and $1 \%$.

The drug content of all formulation is in between $95.23 \%$ and $99.56 \%$.

It is observed that the swelling index of the tablet increases with increase in time up to $24 \mathrm{~h}$, this may be attributed to the fact that the erosion of biodegradable polymer Guar Gum. This indicates that the drug will remain in intestinal region till drug is released completely from the delivery system and promotes evacuation after its release.

In vitro dissolution of quinapril trilayered matrix tablets (AQF16HQF16)

The drug release from quinapril trilayered matrix tablets (AQF16HQF16) was found to extend drug release sustainably up to $24 \mathrm{~h}$,

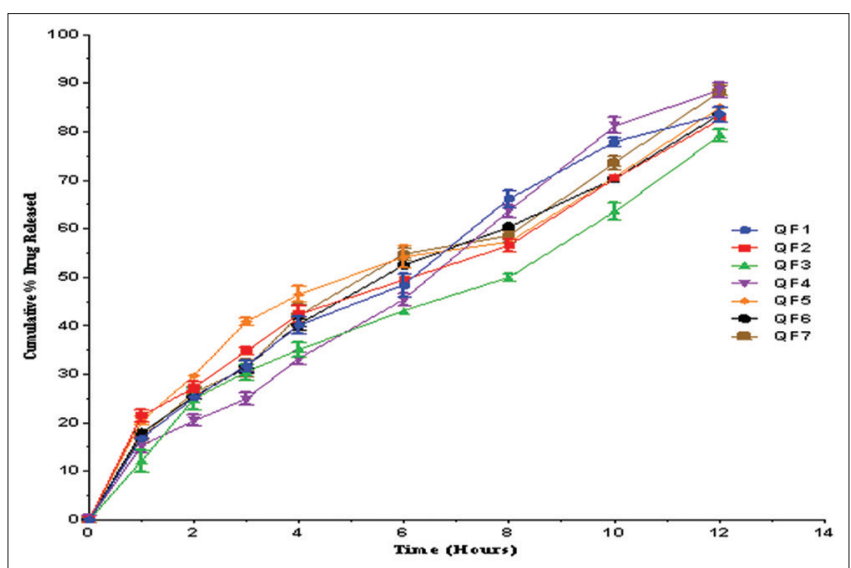

Fig. 2: In vitro drug release profile for prepared middle active layer of quinapril tablets QF1-QF7

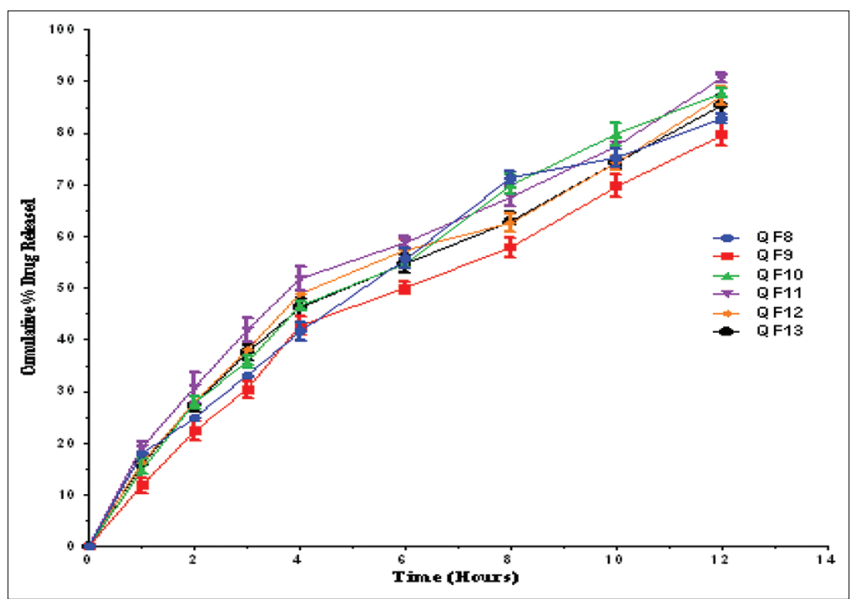

Fig. 3: In vitro drug release profile for prepared middle active layer of quinapril tablets QF8-QF13 and out of all EQF16 was found to show highest drug release of $99.72 \pm 1.11$ (Fig. 6). The drug release was better when compared with the marketed product $(98.16 \pm 1.23)$ and is shown in Fig. 7. Based on other physicochemical properties and drug release EQF16 was chosen as best optimized formulation and is further characterized for Fourier transform infrared (FTIR) and stability studies.

\section{Release kinetics}

From the results, it is apparent that the regression coefficient value (R2) closer to unity in case of zero-order plot for all the formulations (AQF16-HQF16) and out of all EQF16 with highest (R2), that is, 0.9853 indicates that the drug release follows a zero-order mechanism (Table 3). Hence, it can be concluded that the major mechanism of drug release follows zero-order kinetics. Further the $n$ value obtained from the Korsmeyer-Peppas plots, that is, 0.959 indicating non Fickian (anomalous) transport thus it projected that delivered its active ingredient by coupled diffusion and erosion for the marketed product the (R2) closer to unity in case of first-order plot, that is, 0.982 ; hence, it follows first order kinetics.

\section{Design of experiment}

Stat-Ease Design Expert ${ }^{\circledR}$ software V8.0 was utilized for analyzing data, to get regression equation, regression coefficient, and analysis of variance (ANOVA) (Table 4).

\section{\% Swelling index}

A larger swelling index provides a larger surface area for drug absorption. In addition, a larger swelling index may permit a faster

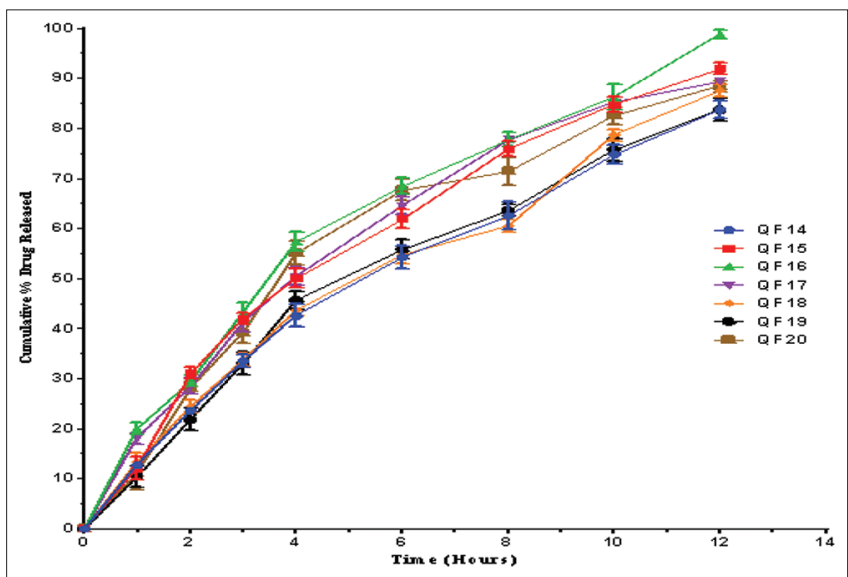

Fig. 4: In vitro drug release profile for prepared middle active layer of quinapril tablets QF14-QF20

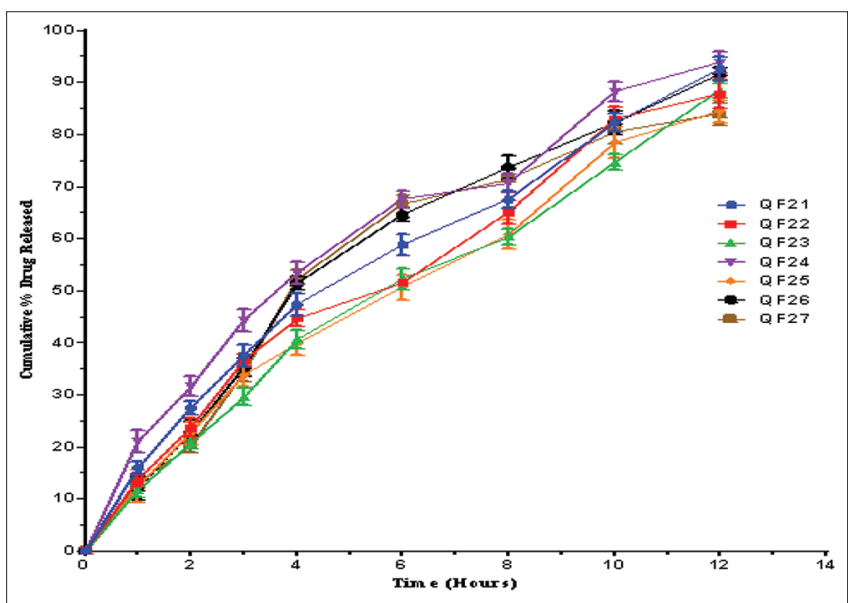

Fig. 5: In vitro drug release profile for prepared middle active layer of quinapril tablets QF21-QF27 


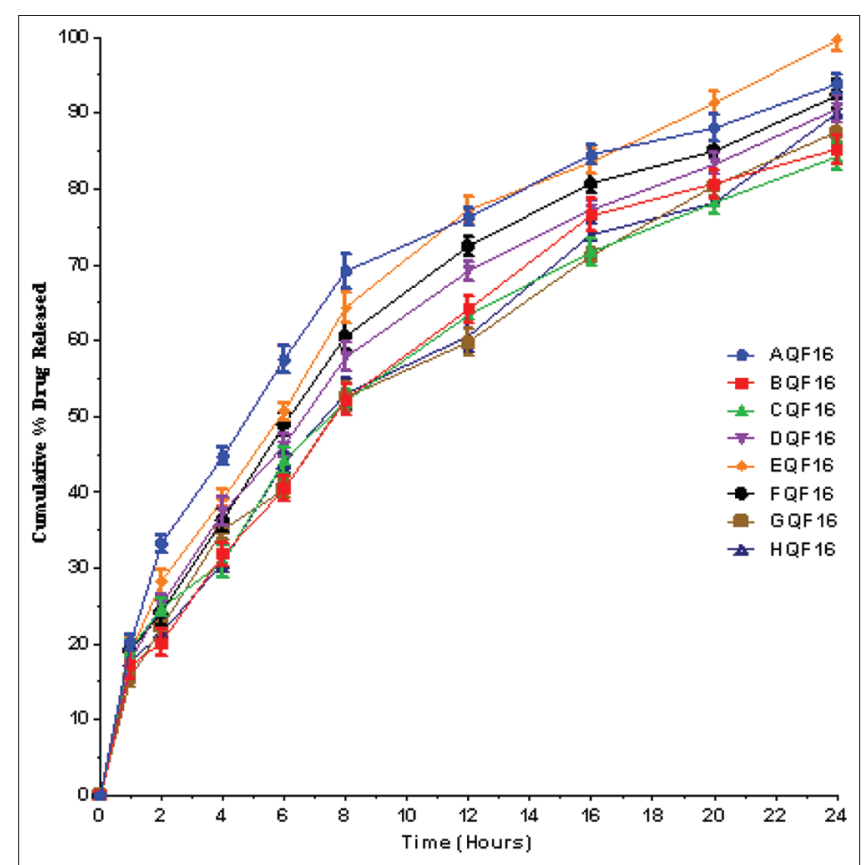

Fig. 6: In vitro dissolution of quinapril trilayered matrix tablets (AQF16-HQF16)

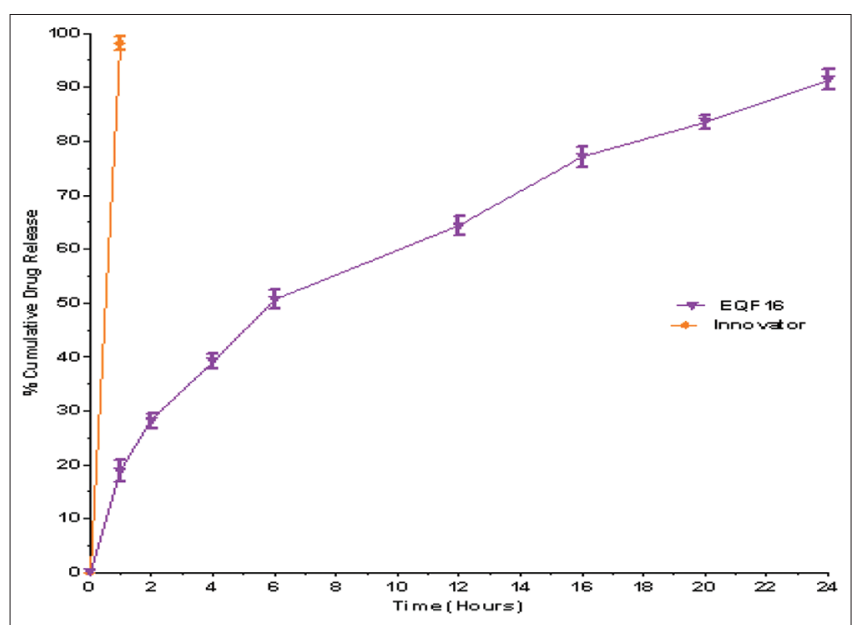

Fig. 7: Comparative in vitro study plot of optimized formulation (EQF16) and conventional marketed tablet

Table 3: Pharmacokinetic Parameters of Quinapril optimized ER tablets formulation and marketed product in rabbit plasma

\begin{tabular}{lll}
\hline $\begin{array}{l}\text { Pharmacokinetic } \\
\text { parameters }\end{array}$ & $\begin{array}{l}\text { Quinapril } \\
\text { marketed product }\end{array}$ & $\begin{array}{l}\text { Quinapril- optimized } \\
\text { ER tablets formulation }\end{array}$ \\
\hline C max (ng/mL) & $358.78 \pm 0.75$ & $302.64 \pm 0.07$ \\
AUC 0-t (ng. h/ml) & $370.64 \pm 1.84$ & $582.64 .64 \pm 1.74$ \\
AUC 0-inf (ng. h/ml) & $381.64 \pm 0.42$ & $608.54 \pm 1.37$ \\
T max (h) & $1.0 \pm 0.03$ & $4.0 \pm 0.06$ \\
t $1 / 2$ (h) & $2.0 \pm 0.02$ & $6.5 \pm 0.04$ \\
\hline
\end{tabular}

release rate. The swelling index of the tablets was found to be in the range of $80.15-98.42 \%$. The quadratic model generated revealed that the amount of HPMC K100M, amount of HPMC K15M, and amount of sodium CMC have a significant influence on the swelling index. The theoretical (predicted) values and the observed values were in reasonably good agreement.

The mathematical model generated for \% swelling index (Y1) was found to be significant with F-value of 0.0128 implies, the model is significant as shown in Fig. 8a and b.

\section{Drug content}

The drug content of the trilayer tablets was found to be in the range of $95.23-99.56 \%$. The quadratic model generated revealed that the amount of HPMC K15M and amount of Sodium CMC have a significant influence on the drug content. The theoretical (predicted) values and the observed values were in reasonably good agreement as seen. The mathematical model generated for drug content (Y2) was found to be significant with F-value of 0.0345 implies, the model is significant as shown in Fig. 9a and b.

\section{Cumulative percent drug released}

The cumulative percent drug release in $24 \mathrm{~h}$ from the Tablets was found to be in the range of $84.24-99.72 \%$. The quadratic model generated revealed that the amount of HPMC K100M, amount of HPMC K15M, and amount of Sodium CMC have a significant influence on the \%CDR. The theoretical (predicted) values and the observed values were in reasonably good agreement as seen. The mathematical model generated for percent drug release in $24 \mathrm{~h}$ (Y3) was found to be significant with F-value of 0.0191 implies, the model is significant as shown in Fig. 10a and b.

\section{Optimization by desirability function}

An optimization process was undertaken with desirability function to optimize the three responses simultaneously. Results are shown in Table 5. The model was proven to be validated since a fine agreement existed between the predicted and observed results. It can be seen that the experimental values were in very close agreement with the predicted values, indicating the success of the central composite design combined with a desirability function for the evaluation and optimization of tablets formulations.

\section{Characterization of optimized quinapril trilayer matrix tablet formulation \\ FTIR studies \\ Characteristics peaks of pure drug FTIR (Fig. 11a) were seen at $2856.67 \mathrm{~cm}^{-1}$ for $\mathrm{N}-\mathrm{H}$ stretching and $\mathrm{C}=\mathrm{O}$ stretching of acid at $1739.85 \mathrm{~cm}^{-1}$. The other principal peaks are at $1535.39 \mathrm{~cm}^{-1}$ for $\mathrm{C}=\mathrm{C}$ stretching, $2505.62 \mathrm{~cm}^{-1}$ for $=\mathrm{C}-\mathrm{H}$ stretching, $3387.11 \mathrm{~cm}^{-1}$ strong and broad band for $\mathrm{O}-\mathrm{H}$ stretching, $1444.73 \mathrm{~cm}^{-1}$ and $1342.50 \mathrm{~cm}^{-1}$ for asymmetric and symmetric bending vibration of $\mathrm{CH} 3$ group, respectively, $1294.28 \mathrm{~cm}^{-1}$ bending vibration for $\mathrm{C}-\mathrm{H}$, and $1143.83 \mathrm{~cm}^{-1}$ for C-F stretching vibrations. The same peaks were observed in optimized formulation (Fig. 11b) and concluded that there was no incompatibility between drug and polymers used in the formulation.}

\section{Stability study}

After subjecting the optimized formulation (EQF16) to the accelerated stability studies, the results were shown that there

Table 4: Optimized values obtained by the constraints applies on Y1, Y2, and Y3

\begin{tabular}{|c|c|c|c|c|c|c|c|c|}
\hline \multirow[t]{2}{*}{ Independent variable } & \multirow{2}{*}{$\begin{array}{l}\text { Nominal } \\
\text { values } \%\end{array}$} & \multicolumn{7}{|c|}{ Predicted values } \\
\hline & & $\begin{array}{l}\text { Swelling index } \\
\text { (Y1) (\%) }\end{array}$ & $\begin{array}{l}\text { Drug content } \\
\text { (\%) (Y2) }\end{array}$ & \%CDR (Y3) & Batch & $\begin{array}{l}\text { Swelling index } \\
\text { (Y1) (\%) }\end{array}$ & $\begin{array}{l}\text { Drug } \\
\text { content (Y2) }\end{array}$ & $\begin{array}{l}\text { Percent drug } \\
\text { released (Y3) }\end{array}$ \\
\hline Amount of HPMC K100M & 42 & 98.42 & 99.56 & 99.72 & 1 & 97.13 & 98.54 & 97.61 \\
\hline Amount of HPMC K15M (B) & 57 & & & & 2 & 96.85 & 98.61 & 96.32 \\
\hline Amount of Sodium CMC (C) & 66 & & & & 3 & 97.63 & 97.69 & 97.73 \\
\hline
\end{tabular}




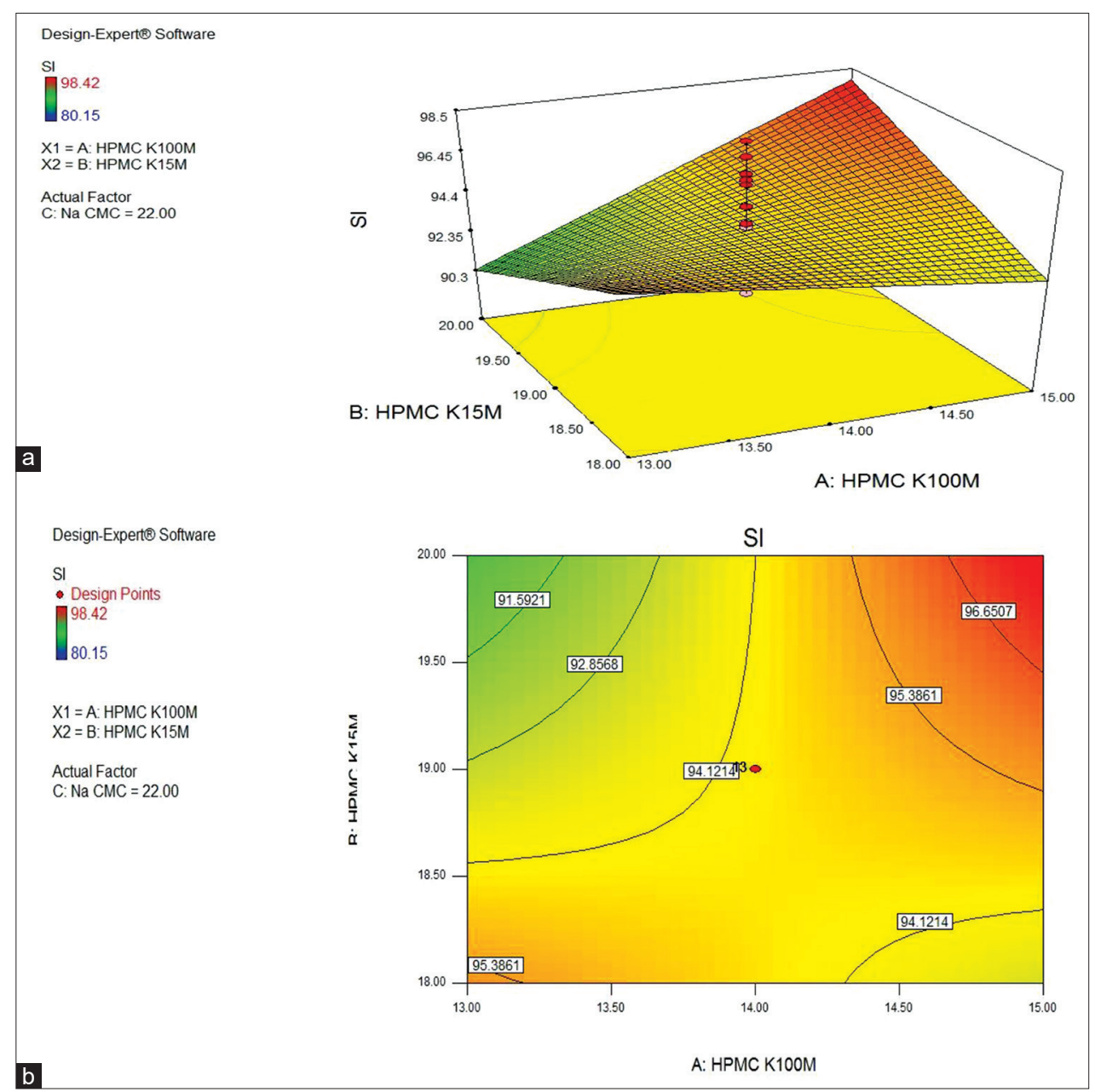

Fig 8: (a) Response 3D surface plot showing the influence of amount of hydroxypropyl methylcellulose (HPMC) K100M and amount of HPMC K15M on Swelling Index fixed level of C. (b) Contour plot showing the influence of amount of HPMC K100M and amount of HPMC K15M on Swelling Index fixed level of C

were no major changes in drug content, in vitro drug release and swelling index. Hence, the formulation was found to be stable (Table 6).

\section{Pharmacokinetic data of quinapril}

The pharmacokinetic parameters were calculated as per the equations explained earlier and the results are shown in Table 3 and Figs. 12-14. $\mathrm{C}_{\max }$ of the quinapril optimized ER tablets formulation $302.64 \pm 0.07 \mathrm{ng} / \mathrm{mL}$ was significant $(\mathrm{p}<0.05)$ as compared to the quinapril marketed product formulation $358.78 \pm 0.75 \mathrm{ng} / \mathrm{mL}$. Tmax of both quinapril optimized ER tablets formulation and quinapril marketed product was $4.0 \pm 0.06$ and $1.0 \pm 0.03 \mathrm{~h}$, respectively. AUC is an important parameter in evaluating bioavailability of drug from dosage form, as it represents the total integrated area under the blood concentration time profile and represents the total amount of drug reaching the systemic circulation after oral

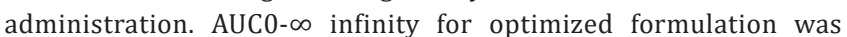
higher $(608.54 \pm 1.37 \mathrm{ng} . \mathrm{h} / \mathrm{ml})$ than the quinapril marketed product formulation $381.64 \pm 0.42 \mathrm{ng} . \mathrm{h} / \mathrm{ml}$. Statistically, AUC0-t of the optimized ER tablets formulation was significantly higher $(\mathrm{p}<0.05)$ as compared to quinapril marketed product formulation. Higher amount of drug concentration in blood indicated better systemic absorption of Quinapril from optimized ER tablets formulation when compared to the quinapril marketed product and also in vivo pharmacokinetic studies in rabbits confirmed the prolonged release by showing increase in bioavailability for Quinapril from optimized ER tablets formulation as compared to the quinapril marketed product formulation.
Table 5: Parameters after accelerated stability study of formulation EQF16

\begin{tabular}{|c|c|c|c|c|}
\hline \multirow[t]{2}{*}{ Parameters } & \multicolumn{4}{|c|}{$\begin{array}{l}\text { Temperature Maintained at } 40 \pm 20 \mathrm{C} \text {; } \\
\text { Relative Humidity }(\mathrm{RH}) \text { Maintained at } \\
75 \% \pm 5 \% \mathrm{RH}\end{array}$} \\
\hline & Initial & $\begin{array}{l}\text { After } 1 \\
\text { month }\end{array}$ & $\begin{array}{l}\text { After } 2 \\
\text { months }\end{array}$ & $\begin{array}{l}\text { After } 3 \\
\text { months }\end{array}$ \\
\hline Drug content (\%) & $99.56 \pm 0.14$ & $99.09 \pm 1$ & $99.05 \pm 1.42$ & $99.02 \pm 1.35$ \\
\hline $\begin{array}{l}\text { In vitro drug } \\
\text { release (\%) }\end{array}$ & $99.72 \pm 1.11$ & $99.56 \pm 1.68$ & $99.43 \pm 1.37$ & $99.361 \pm 1.22$ \\
\hline Swelling index & $98.42 \pm 0.64$ & $98.33 \pm 1.78$ & $98.26 \pm 1.55$ & $98.18 \pm 1.24$ \\
\hline
\end{tabular}

Values are expressed in mean \pm SD: $(n=3)$

Table 6: Regression equations of the fitted models

\begin{tabular}{ll}
\hline Response & Equation \\
\hline Swelling index (Y1) & $85.42+09.67 \mathrm{X} 1-14.23 \mathrm{X} 2-2.60$ \\
& $\mathrm{X} 3-0.88 \mathrm{X} 21+0.21 \mathrm{X} 1 \mathrm{X} 3+12.54 \mathrm{X} 22-2.15$ \\
& $\mathrm{X} 2 \mathrm{X} 3+1.79 \mathrm{X} 23$ \\
Drug content (Y2) & $79.54+08.13 \mathrm{X} 1+13.41 \mathrm{X} 2+3.74$ \\
& $\mathrm{X} 3+0.18 \mathrm{X} 21-0.45 \mathrm{X} 1 \mathrm{X} 3-13.59 \mathrm{X} 22-2.52$ \\
& $\mathrm{X} 2 \mathrm{X} 3-3.15 \mathrm{X} 23$ \\
\% Cumulative drug & $68.13-2.84 \mathrm{X} 1+22.18 \mathrm{X} 2-19.63$ \\
released (Y3) & $\mathrm{X} 3+0.47 \mathrm{X} 21-12.33 \mathrm{X} 1 \mathrm{X} 3+06.75 \mathrm{X} 22-38.65$ \\
& $\mathrm{X} 2 \mathrm{X} 3+2.40 \mathrm{X} 23$ \\
\hline
\end{tabular}

Where $\mathrm{Y} 1, \mathrm{Y} 2$, and $\mathrm{Y} 3$ are the predicted response and $\mathrm{X} 1, \mathrm{X} 2$, and $\mathrm{X} 3$ are the coded values of the test variables in respective concentrations 


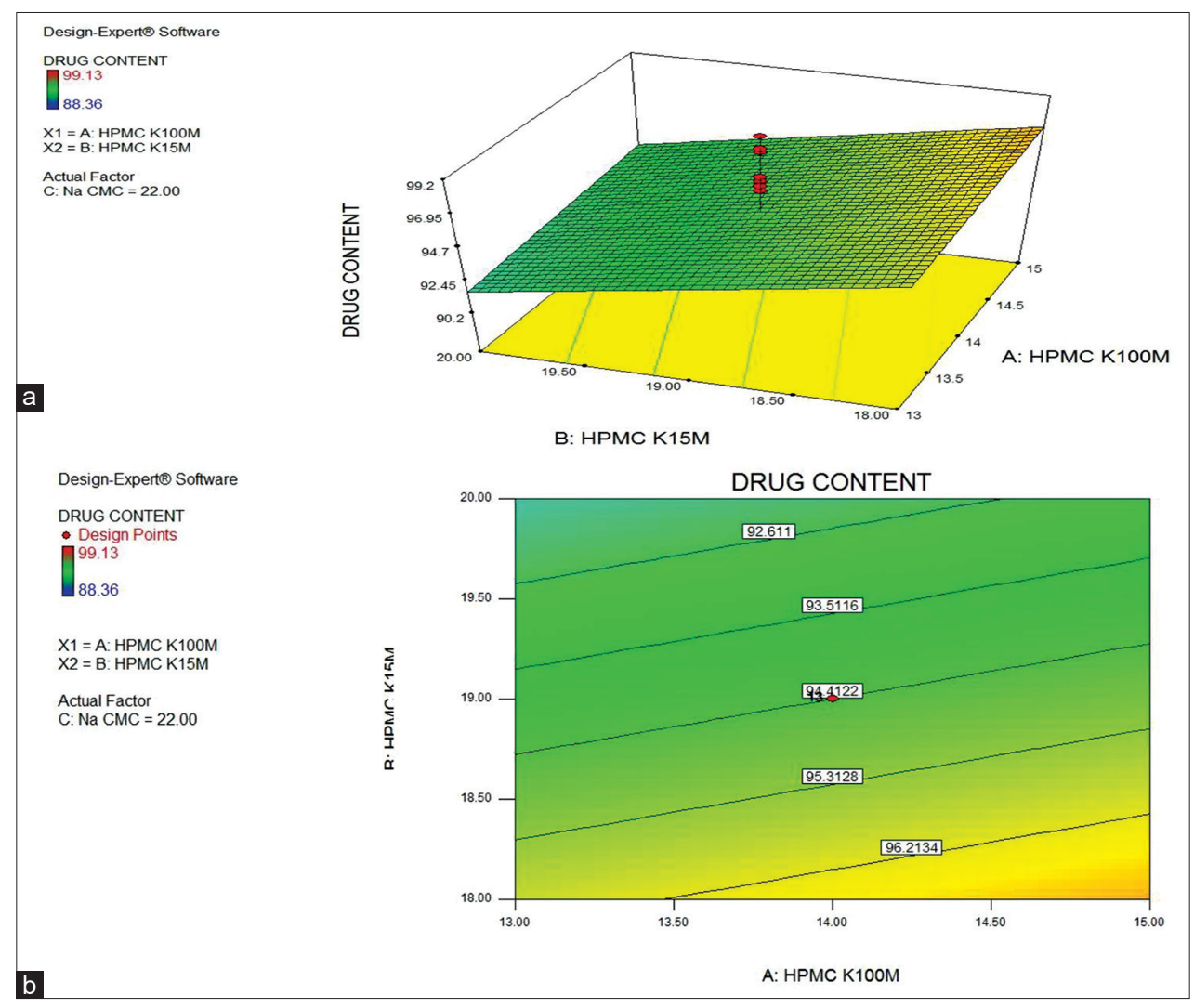

Fig. 9: (a) Response 3D surface plot showing the influence of amount of hydroxypropyl methylcellulose (HPMC) K100M and amount of HPMC K15M on Drug Content fixed level of C. (b) Contour plot showing the influence of amount of HPMC K100M and amount of HPMC K15M on drug content fixed level of $C$

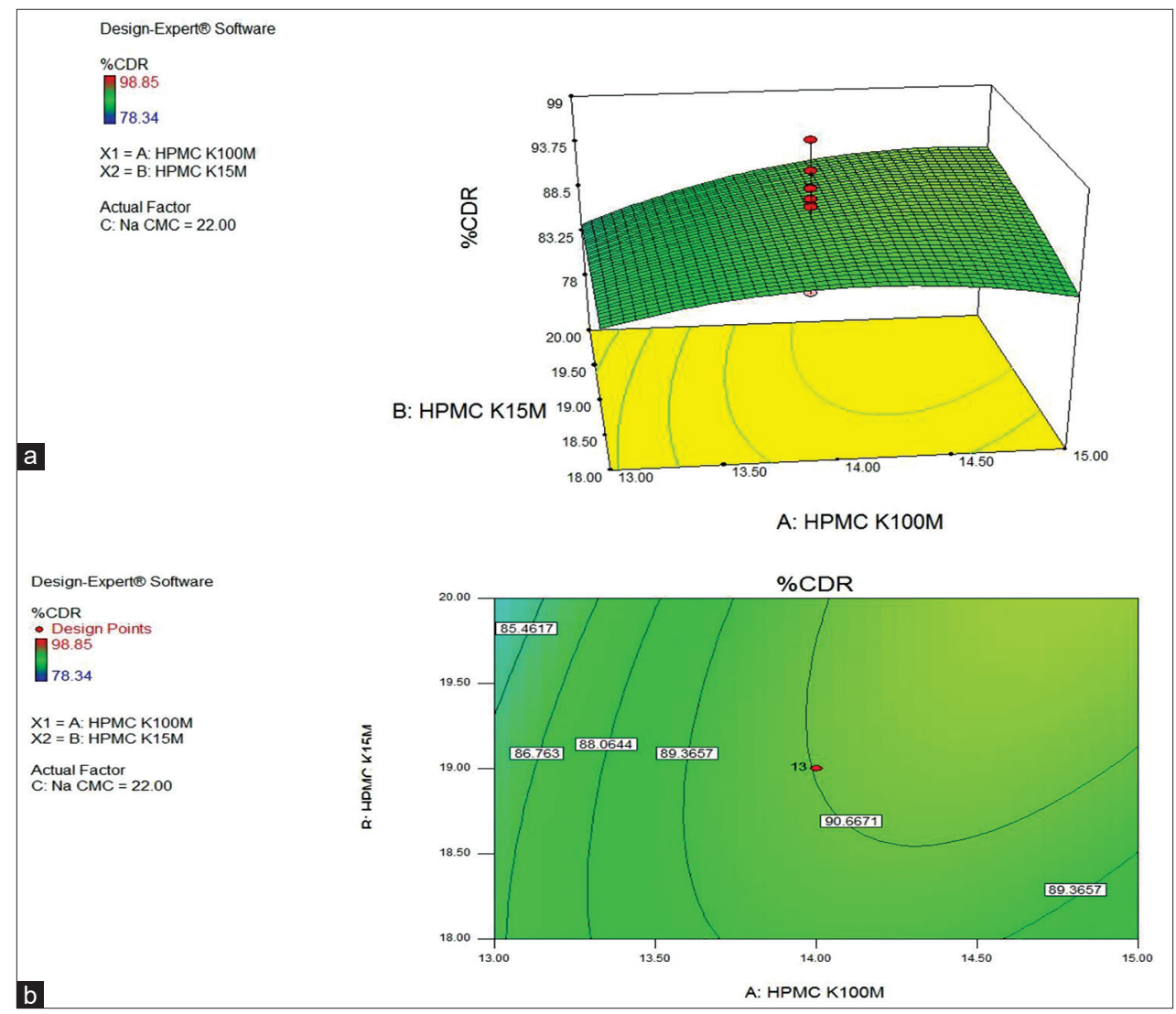

Fig. 10: (a) Response 3D surface plot showing the influence of amount of hydroxypropyl methylcellulose (HPMC) K100M and amount of HPMC K15M on Cumulative \% Drug Released level of C. (b) Contour plot showing the influence of amount of HPMC K100M and amount of HPMC K15M on cumulative \% drug released level of $c$ 


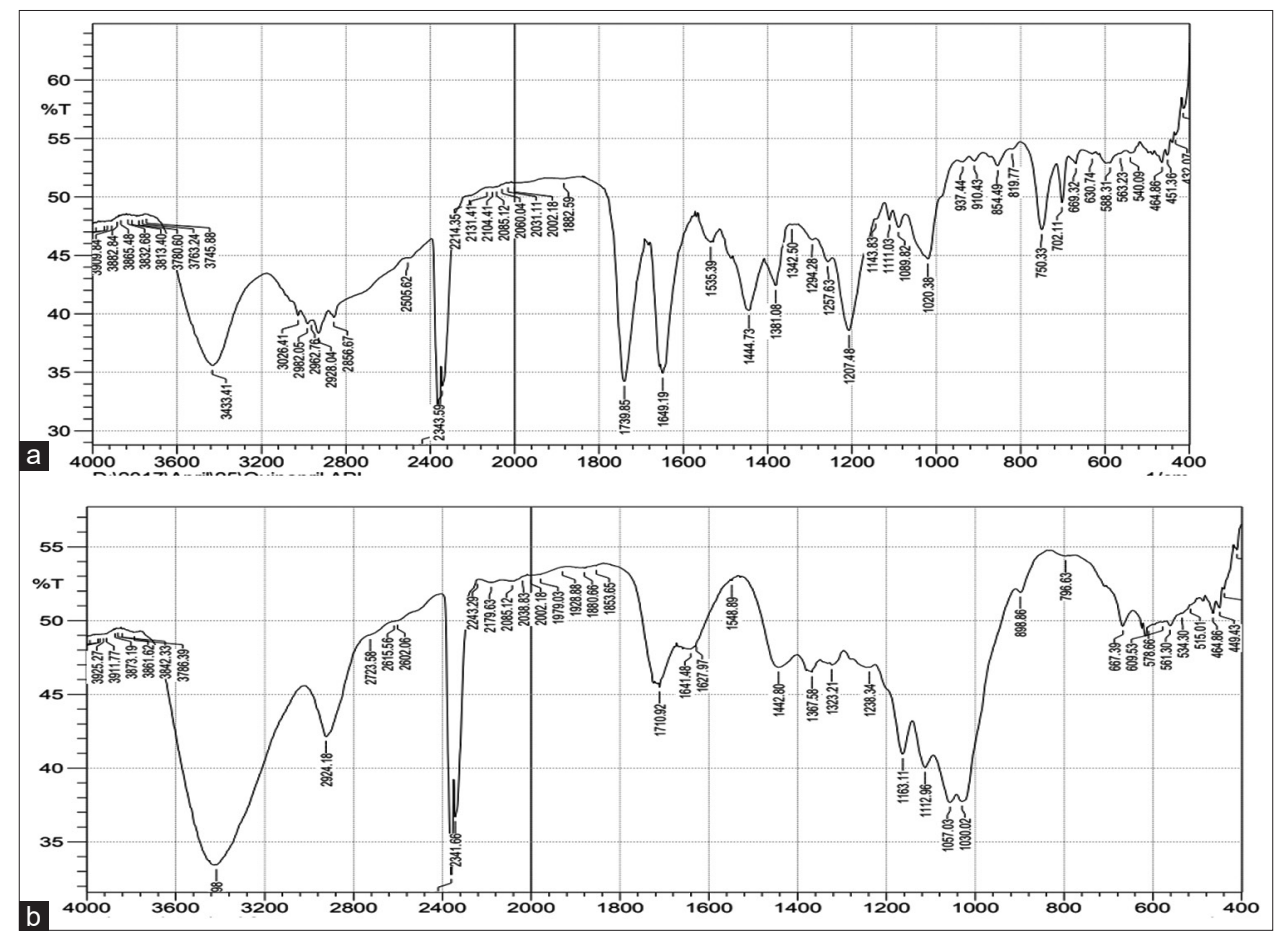

Fig. 11: (a) Fourier transform infrared (FTIR) spectroscopy of quinapril pure drug. (b) FTIR spectrum of quinapril optimized formulation EQF16

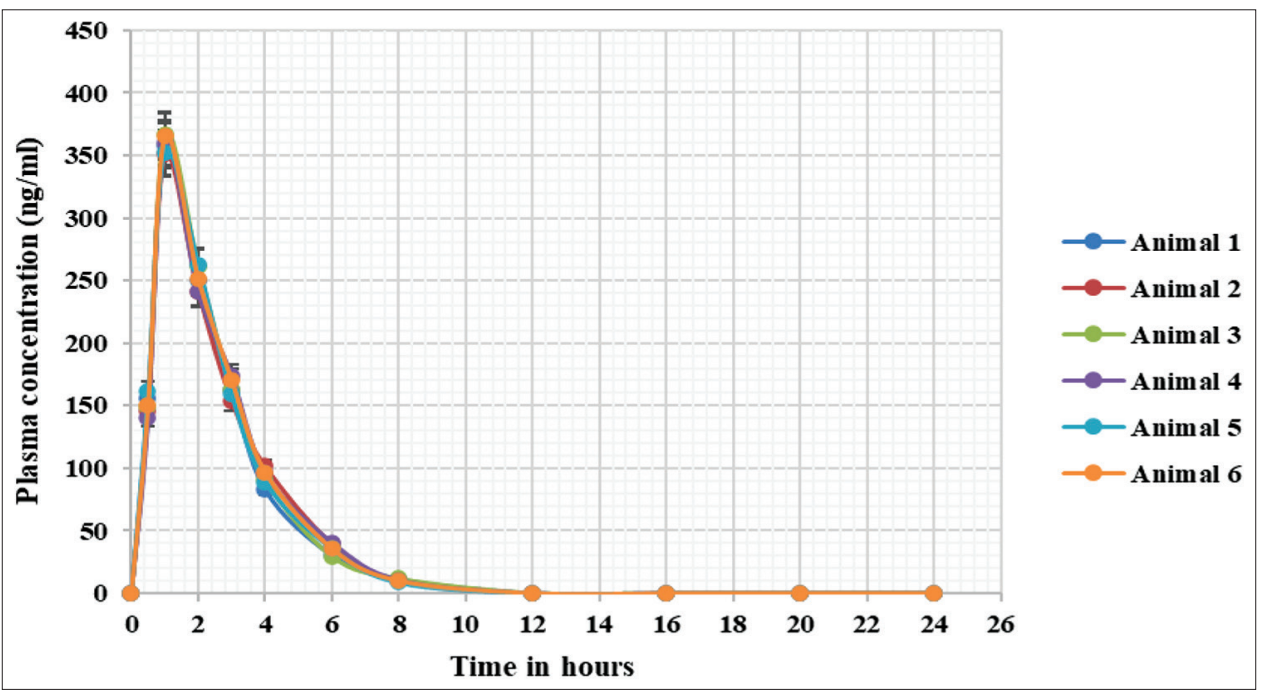

Fig. 12: Plasma concentration-time profile of quinapril marketed product in rabbit plasma

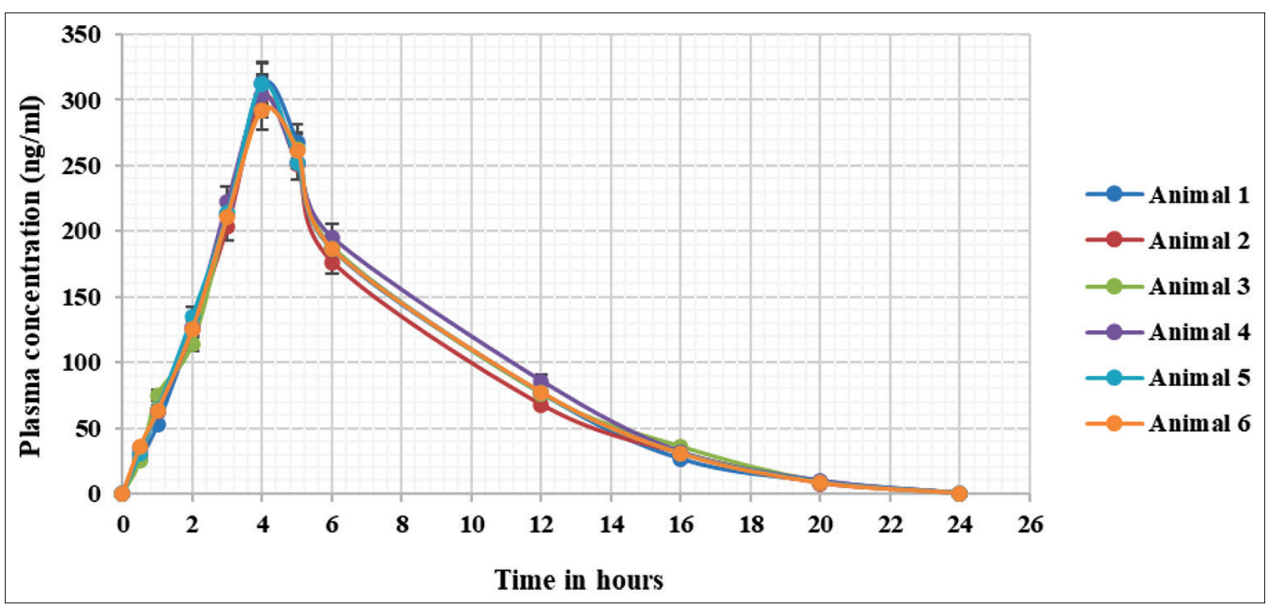

Fig. 13: Plasma concentration-time profile of quinapril optimized ER tablets optimized in rabbit plasma 


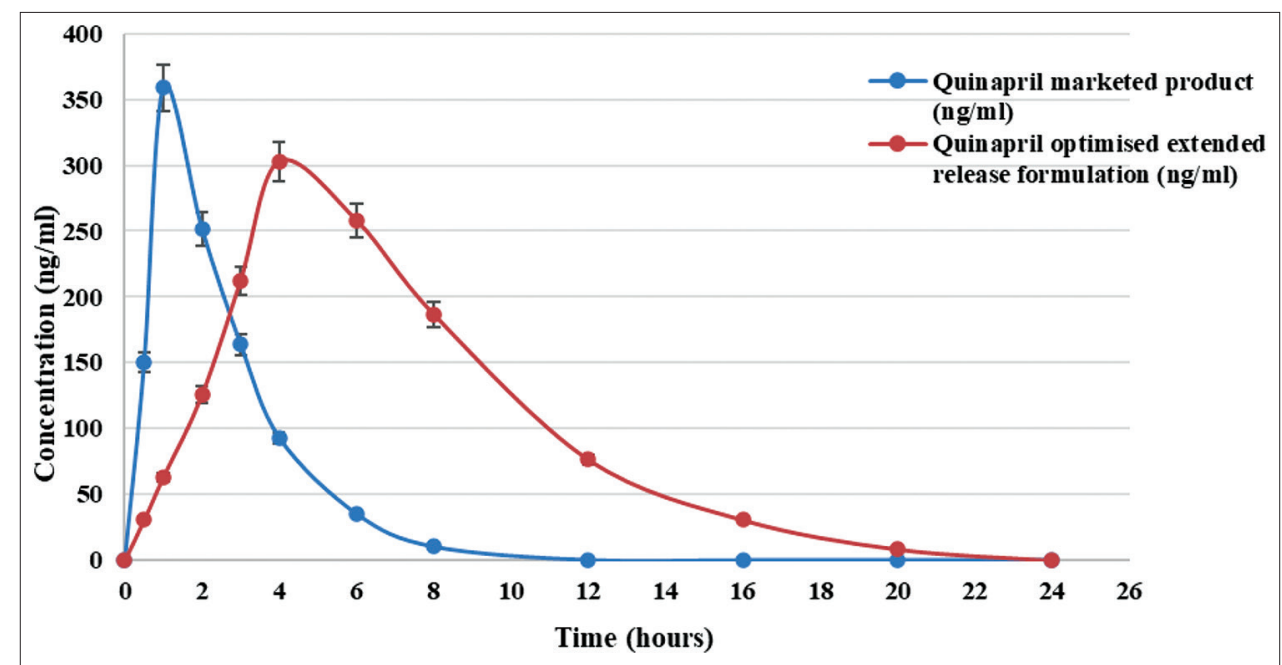

Fig. 14: Plasma concentration profiles of quinapril optimized ER tablets and marketed product in rabbit plasma

\section{CONCLUSION}

It is concluded from the results that trilayered matrix tablets of quinapril were successfully prepared using $3^{3}$ Response surface method using Design of experiment software. Out of 27 formulations QF16 was found to exhibit good physicochemical properties and highest drug release of $98.85 \%$ and was chosen for formulation into extended release trilayered matrix tablets by varying proportions of polymers and they were evaluated (AQF16-HQF16). The physicochemical properties such as swelling index which ranged from $80.15 \%$ to $98.42 \%$, and drug content of $95.23 \%-99.56 \%$ were within the limits with highest values exhibited by EQF16. Maximum drug was released from the formulation EQF16 (99.72) within $24 \mathrm{~h}$. Based on the physicochemical properties and in vitro drug release, the formulation EQF16 was concluded as the best formulation. FTIR studies indicated no interaction of drug with excipients and EQF16 was loaded for stability exhibited no significant changes. The in vivo studies conducted showed Cmax of the EQF16 formulation $302.64 \pm 0.07 \mathrm{ng} / \mathrm{mL}$ was significant $(\mathrm{p}<0.05)$ as compared to the quinapril marketed product formulation $358.78 \pm 0.75 \mathrm{ng} / \mathrm{mL}$ and AUC0-t of the EQF16 was significantly higher $(\mathrm{p}<0.05)$ than marketed. The pharmacokinetic studies confirmed the extended release by showing increase in bioavailability for quinapril trilayer matrix tablets than marketed.

\section{AUTHOR CONTRIBUTIONS}

All authors are contributed equally.

\section{CONFLICT OF INTEREST}

The authors declare no conflict of interest, financial, or otherwise.

\section{REFERENCES}

1. Ho-Wah H, Robinson J, Lee V. Design and fabrication of oral controlled release drug delivery systems. In: Controlled Drug Delivery. New York: Marcell Dekker Inc.; 1987. p. 373.

2. Conte U, Maggi L. Multi-layer tablets as drug delivery devices. Pharm Technol 1998;2:18-25.

3. Kitt J. New approaches in hypertension management: A review of current and developing technologies and their potential impact on hypertension care. Curr Hypertens Rep 2019;21:44
4. Syed IA, Mangamoori LN, Rao YM. Formulation and characterization of matrix and triple-layer matrix tablets for controlled delivery of metoprolol tartrate. Int J Pharm Sci Drug Res 2011;3:23-8.

5. Gohel MC, Bariya SH. Hypromellose and polyethylene oxide: Comparative formulation design of triple-layer tablets. J Pharm Res 2010;3:2223-7.

6. Srinivas MP, Chaitanya N. Formulation and evaluation of sitagliptin phosphate and metformin hydrochloride trilayered tablets. Int J Drug Deliv 2013;5:15-27.

7. Efentakis M, Peponaki C. Formulation study and evaluation of matrix and three-layer tablet sustained drug delivery systems based on carbopols with isosorbite mononitrate. AAPS PharmSci Tech 2008;9:917-23.

8. Krishnaiah YS, Karthikeyan RS, Bhaskar P, Satyanarayana V. Bioavailability studies on guar gum-based three-layer matrix tablets of trimetazidine dihydrochloride in human volunteer. J Control Release 2002;83:231-9.

9. Lordi NG. Sustained release dosage forms. In: The Theory and Practice of Industrial Pharmacy. $3^{\text {rd }}$ ed. Mumbai: Varghese Publishing House; 2008. p. 430-54

10. Patil R, Vishal, P, Sonawane R. Nano and microparticulate chitosan based system for formulation of carvedilol rapid melt tablet. APB 2015;5:169-79.

11. Talukdar MM, Mooter VD, Augustijns P, Maga TT, Verbeke N, Kinget R. In vitro evaluation of guar gum as potential excipients for oral controlled release matrix tablet formulation. Int $\mathrm{J}$ Pharm 1998;169:10513.

12. Yang L, Fassihi R. Accessibility of solid core tablet for dissolution in a asymmetric triple-layer matrix system. J Pharm Pharmcol 2003;55:1331.

13. Karadag E. In vitro swelling studies and preliminary biocompatibility evaluation of acrylamide-based hydrogels. Biomaterials 1996;17:67-7.

14. Bozal-Palabiyik B, Uslu B, Ozkan Y, Ozkan SA. In-vitro drug dissolution studies in medicinal compounds. Curr Med Chem 2018;25:4020-36.

15. Chidambaram N, Porter W, Flood K, Qiu Y. Formulation and characterization of new layered diffusion matrices for zero-order systained release. J Control Release 1998;52:149-58.

16. Sharma PR, Lewis SA. Design and in vitro/in vivo evaluation of extended-release matrix tablets of nateglinide. J Young Pharm 2013;5:167-72.

17. Altunsoy S, Bozal-Palabiyik B, Uslu B. Validation of liquid chromatographic method for simultaneous determination of quinapril and hydrochlorothiazide in pharmaceutical dosage forms. Turk J Pharm Sci 2013;10:255-62. 